\title{
New Configurations of a Heat Recovery Absorption Heat Pump Integrated with a Natural Gas Boiler for Boiler Efficiency Improvement
}

\author{
Ming $\mathrm{Qu}^{\mathrm{a} *}$, Omar Abdelaziz ${ }^{\mathrm{b}}$, Hongxi Yin ${ }^{\mathrm{c}}$ \\ ${ }^{a}$ Purdue University, School of Civil Engineering, West Lafayette, IN, 47906, USA \\ ${ }^{\mathrm{b}}$ Oak Ridge National Laboratory, Building Equipment Research, Energy \& Transportation Science \\ Division, Oak Ridge, TN 37831, USA \\ ${ }^{\mathrm{c}}$ Southeast University, School of Architecture, Nanjing, 210096, China \\ Corresponding author: \\ Ming Qu \\ Purdue University \\ School of Civil Engineering \\ 550 Stadium Mall Drive \\ West Lafayette, IN 47907-2051 \\ Tel: $\quad 1-765-494-9125$ \\ Email: $\quad$ mqu@purdue.edu
}

\begin{abstract}
Conventional natural gas-fired boilers exhaust flue gas direct to the atmosphere at $150-200^{\circ} \mathrm{C}$, which, at such temperatures, contains large amount of energy and results in relatively low thermal efficiency ranging from $70 \%$ to $80 \%$. Although condensing boilers for recovering the heat in the flue gas have been developed over the past 40 years, their present market share is still less than $25 \%$. The major reason for this relatively slow acceptance is the limited improvement in the thermal efficiency of condensing boilers. In the condensing boiler, the temperature of the hot water return at the range of $50-60^{\circ} \mathrm{C}$, which is used to cool the flue gas, is very close to the dew point of the water vapor in the flue gas. Therefore, the latent heat, the majority of the waste heat in the flue gas, which is contained in the water vapor, cannot be recovered. This paper presents a new approach to improve boiler thermal efficiency by integrating absorption heat pumps with natural gas boilers for waste heat recovery (HRAHP). Three configurations
\end{abstract}


of HRAHPs are introduced and discussed. The three configurations are modeled in detail to illustrate the significant thermal efficiency improvement they attain. Further, for conceptual proof and validation, an existing hot water-driven absorption chiller is operated as a heat pump at operating conditions similar to one of the devised configurations. An overall system performance and economic analysis are provided for decision-making and as evidence of the potential benefits. These three configurations of HRAHP provide a pathway to achieving realistic high-efficiency natural gas boilers for applications with process fluid return temperatures higher than or close to the dew point of the water vapor in the flue gas.

Keywords: Natural gas boiler, absorption heat pump, heat recovery, dew point, flue gas, system configuration

\section{Nomenclature}

$\eta_{\text {overall- }}$ overall thermal efficiency of the HRAHP and the boiler, non-dimensional

$\dot{Q}_{h w}$ - heating energy produced, kW

$\dot{Q}_{\text {inp } u t}$ - energy input, kW

$\dot{m}_{h w}$-flow rate of the applied hot water, $\mathrm{kg} / \mathrm{s}$

$C p_{\text {hw }}$-specific heat of water, $\mathrm{kJ} / \mathrm{kg}{ }^{\circ} \mathrm{C}$

$T_{\text {hws }}$-hot water supply temperature, ${ }^{\circ} \mathrm{C}$

$T_{\text {hwr }}$ - hot water return temperature, ${ }^{\circ} \mathrm{C}$

Cap $_{\text {boiler }}$ - heat capacity of the boiler, $\mathrm{kW}$

$H_{\text {boiler- }}$ thermal efficiency of the boiler, non-dimensional

$\dot{Q}_{a d d^{-}}$additional energy input, $\mathrm{kW}$

$\eta_{\mathrm{df}}-$ the efficiency loss due to high temperature dry flue gas

$\eta_{\text {vapor } \_ \text {g }}$ - the efficiency loss due to the water vapor of the products released with the flue gas. 
$\eta_{\text {airmoisture } \_ \text {g }}$ - the efficiency loss due to the vapor from air can be calculated in the similar logic as the heat loss due to vapor in flue gas

$\eta_{\text {radiation }}$-the efficiency loss due to radiation from boiler

$\eta_{\text {blowdown-the efficiency loss due to blowdown water }}$

$\eta_{\text {others }}$-the efficiency loss due to others

\section{Introduction}

Natural gas-fired boilers have gradually dominated the process heating sector due to their high thermal efficiency, relatively low emissions, and convenient fuel delivery system. A conventional natural gasfired boiler typically has a thermal efficiency in the range of $70-80 \%{ }^{1}$. Normally, the boilers directly exhaust the flue gas at temperatures of $150-200^{\circ} \mathrm{C}$ to avoid the corrosion caused by the condensation of water vapor in the flue gas. However, discarding the flue gas at such high temperatures causes a large amount of heat loss. If the heat, especially the latent heat, contained in the flue gas can be recovered, the thermal efficiency of a natural gas boiler could be significantly improved.

In the 1970s, condensing boilers were invented to recover the latent heat of the water vapor contained in the flue gas of natural gas boilers. The condensing boiler has a flue gas condenser installed at the exit of the flue gas of a conventional gas boiler where the flue gas is cooled to a temperature lower than the dew point of the water vapor in the flue gas before it exits the boiler. Thus, the condensing boiler can have higher efficiency, depending upon the temperature of the exit flue gas. Regarding the relationship

\footnotetext{
${ }^{1}$ The efficiencies in this paper are based on the higher heating value of natural gas, $22.884 \mathrm{MJ} / \mathrm{kg}$, which is $2.79 \mathrm{MJ} / \mathrm{kg}$ higher than the lower heating value of natural gas.
} 
between boiler efficiency and exit flue gas, Che et al [1] found that the thermal efficiency of a gas-fired boiler could be improved from 16.8 to $15.1 \%$ if the flue gas temperature is reduced to $25-35^{\circ} \mathrm{C}$. In addition, the SOx, NOx, dust, and soot of the flue gas constituents can be partially, even totally, dissolved in the water condensation, so that the pollutants emitted by the boilers can be remarkably reduced. Weber et al [2] estimated that condensing gas boilers could save $5 \%$ of the primary energy and $4 \%$ of the $\mathrm{CO}_{2}$ emissions if they are applied to residential space heating in the EU. According to the study of Searle et al [3] the payback of a condensing boiler installed was estimated to be between 3 and 4.5 years. However, Boeschen [4] reported that the actual simple payback of a modular condensing boiler installed in a U.S. government office building in Sioux City, Iowa, was 24 years. This big difference between the estimated and actual payback years indicates that many design and installation parameters significantly influence the performance of condensing boilers in their specific applications. Among them, the operating temperature and thermal mass of the media used to cool the flue gas in the condensing boilers are considered to be the most important factors. Typically, the media used in practice are the hot water return from buildings or the process in the heating water loop due to economics and system sustainability. The temperatures of the hot water return are normally in the range of $50-60^{\circ} \mathrm{C}$, which are close to the dew point of the water vapor in the flue gas. Hence, the water vapor in the flue gas cannot be condensed completely and the latent heat in the flue gas cannot be fully recovered. Therefore, the efficiency improvement by the condensing boilers is very limited practically, especially for commercial buildings. This is one of the major reasons why condensing boilers have continued to have less than $25 \%$ of the market share in the last 40 years.

In this paper, we introduce a new approach to improve the thermal efficiency of natural gas boilers: using an absorption heat pump (AHP) integrated with heat exchangers to recover the waste heat, especially the latent heat in the boiler flue gas, by using the hot water return from buildings or processes. This paper focuses on the conceptual development of the heat recovery absorption heat pump (HRAHP) for natural gas boilers to improve boiler thermal efficiency by 5-10\%. The tremendous economic, energy, and 
environmental benefits due to the HRAHP can lead to widespread deployment of gas-fired boilers and further promote sustainable development.

Absorption heat pumps (AHPs), similar to absorption chillers, transfer heat from a low temperature reservoir to a high temperature reservoir by using thermal energy. AHPs are designed to deliver heating, and also cooling. The thermal efficiency of AHPs, also called the Coefficient of Performance (COP), for cooling, is the ratio of the energy absorbed by the evaporator to the thermal inputs and, for heating, is the ratio of the sum of the energy rejected by the condenser and the absorber to the thermal inputs. AHPs are significantly different from absorption heat transformers, which are also well-known absorption applications. In an absorption heat transformer, the desorber is operated at lower temperatures and lower pressures than the evaporator in the cycle; but in an AHP, the desorber runs at higher temperatures and higher pressure than the evaporator. Currently, the most widely used working fluid pairs in AHPs are the ammonia-water and the water-lithium bromide $(\mathrm{LiBr})$. The thermal energy to drive AHPs can be from a great variety of media that include exhausted gas, hot fluid from solar or geothermal, wasted heat from cogeneration or process steam plants, and natural gas.

Many researchers investigated various types of AHPs coupled with geothermal systems and waste heat in the past [7-11]. S. Jeong [8] concluded that the heating capacity of AHP increases with increases in the heat transfer area for waste heat recovery. C. Keil [11] reported three applications of customized AHPs in low temperature local heating systems by using heat from combined heating and power systems or other resources. Keil's research proved that AHPs can achieve high energy efficiency and short payback periods of only a few years. L. Fu et al [13] used a demonstration system consisting of a gas-powered internal combustion engine integrated with an exhaust-gas-driven AHP to recover the flue gas to prove the feasibility of using flue gas condensation heat as a low grade heat resource for an AHP. Solar-driven AHP systems were reviewed by Grossman [12]. Additionally, a few researchers focused on mathematical models and performance analyses for AHP based on mass and energy balances [8, 13-17]. Others have explored an AHP integrated with a gas-fired boiler for higher thermal efficiencies, however, both Chen 
and $\mathrm{Fu}$ provided their review on a potential AHP for recovering the heat in the flue gas but without detailed analysis on system and performance $[18,19]$.

This paper introduces and illustrates HRAHPs as a technology to fully recover the waste heat from gas boilers by using the return of the process heating fluid in a typical heating system. The system performance models of three alternative system configurations have been developed according to heat and mass transfer and thermodynamics principles. Experiments on a hot water-driven absorption heat pump were conducted to validate the corresponding model and further prove the performance models for the three alternative system configurations. The organization of this paper is as follows: the research methodology, the HRAHP system configurations, system performance modeling, model results and predicted performance, experiments and model validation, simple economic analysis for HRAHPs, and conclusions and discussion.

\section{Research Method}

The HRAHP is an energy efficiency system based upon absorption technology integrated with conventional gas boilers to recover some or all of the waste heat in the flue gas. We first explored the three feasible system configurations to enable the optimal system performance. The thermal dynamics and heat transfer computational models then were developed to simulate the operating conditions and predict performance for the combustion of the natural gas boiler, the AHPs, and the integrated HRAHPs. The boiler combustion model was developed for predicting the composition, and the physical and thermal properties of the flue gas in Engineering Equation Solver (EES) [20]. The AHPs were modeled using ABsorption SIMulation (ABSIM) to evaluate the working states and system performance. ABSIM is a tool developed in 1998 by the Oak Ridge National Laboratory for the simulation of absorption systems [21]. Based on the natural gas boiler combustion model and the AHP models developed in the ABSIM models, the overall HRAHP system models finally were developed in EES to evaluate the overall system efficiency and performance. In order to prove the feasibility of the HRAHP technology, since no HRAHP system currently exists, we designed and conducted performance tests at the component level. We tested a 
hot water-driven AHP for the validation of the corresponding AHP model. Since the AHP models used in the overall HRAHP system models are at the same basis setting as the AHP models for the tested equipment, the experiment further proved the predictions by the AHP models used in the HRAHP models. In order to provide a complete review of the HRAHP, simple economic analyses for the three HRAHP alternatives were conducted to provide more insights about the HRAHP systems.

\section{HRAHP System Configurations}

The designed HRAHP system consists of an absorption heat pump (AHP) and two heat exchangers, HX-1 and HX-2, to recover the waste heat in the flue gas exhausted from a natural gas boiler, as shown in Figure 1. The HX-1 is designed as a gas-liquid heat exchanger for recovering the sensible heat in the flue gas by using a hot water return, while the HX-2 is designed as a condensing heat exchanger for recovering the latent heat in the flue gas. Thus, the corrosion due to the condensation of the flue gas could be intensively considered in the HX-2 design. The temperature of the flue gas after the HX-1 is designed approximately at $60^{\circ} \mathrm{C}$, which continuously cools the flue at approximately $35^{\circ} \mathrm{C}$ after the $\mathrm{HX}-2$ by using the chilled water produced by the AHP.

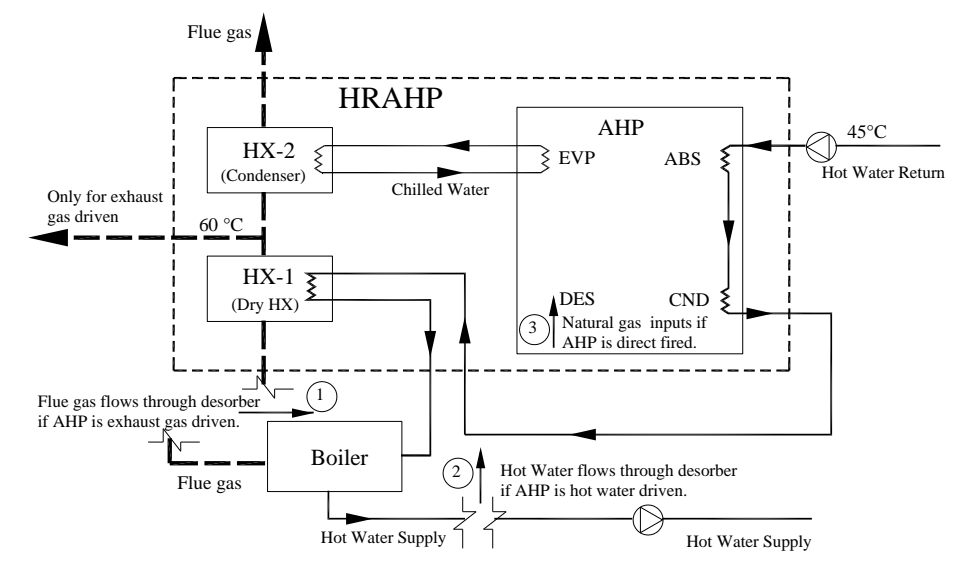

Figure 1 Schematic system diagram for the HRAHP

The AHP can be driven by three various thermal resources available in a HRAHP system: the flue gas exhausted from the boiler, the hot water produced by the boiler, and natural gas. The three thermal resource options are marked as(1),2), and (3)in Figure 1, respectively. For instance, if the AHP is driven by the flue gas, the flue gas first flows through the absorber and then goes through HX-1 and HX-2 
sequentially. More detailed system configurations for the three types of HRAHP can be viewed in Figures 4, 5, and 6. We consider the AHPs as single effect absorption machines, and the chilled water supply temperature from the evaporator of the AHPs is in the range of $20-25^{\circ} \mathrm{C}$ for recovering the latent heat in the flue gas through HX-2 so that the energy ratio of the chilled water production and the thermal resource was in the range of 0.6-0.8. The energy ratio of the hot water production and the thermal resource in the HRAHP was in the range of 1.5-1.8. The hot water return from the building or process (termed as hot water throughout this paper for brevity) was assumed to be $45^{\circ} \mathrm{C}$. Considering the temperature elevations in the absorber, the condenser, and the cold stream requirement of the $\mathrm{HX}-1$, the hot water return was arranged to flow through the absorber first, then the condenser, the HX-1, and lastly to feed back to the boiler, which heats it to the desired temperature as the hot water supply.

It is possible for both hot water- and natural gas-driven HRAHPs to fully recover the flue gas from the boiler by using the hot water return and the chilled water generated by the AHP. However, in the exhaust gas HRAHP, the flue gas from the boiler was used as the thermal input (first flowing through the desorber) and then passed through HX-1 and HX-2 for heat recovery. According to the energy balance analysis, it is not possible to fully recover the energy contained in the flue gas if the same amount of flue gas flows through all three places. As indicated in Figure 1, the latent energy of the flue gas, recovered in HX-2 through the condensation, was equal to the chilled water energy generated in the evaporator of the AHP. The chilled water produced by a single effect AHP is roughly $70 \%$ of the energy inputs, which are the sensible heat of the flue gas used by the absorber in the AHP. Therefore, the latent energy of the flue gas recovered by HX-2 can only be $70 \%$ of the sensible heat of flue gas recovered by the desorber. However, if we assume the dew point of $1 \mathrm{~kg}$ flue gas is $55^{\circ} \mathrm{C}$, then the latent energy released by condensing water vapor at $55^{\circ} \mathrm{C}$ is around $2,369.8 \mathrm{~kJ} / \mathrm{kg}$, while the sensible energy removed from the flue gas to reduce its temperature from $150^{\circ} \mathrm{C}$ to $55^{\circ} \mathrm{C}$ is about $146 \mathrm{~kJ} / \mathrm{kg}$. Hence, if the same amount of the flue gas passes through both the HX-2 and the desorber, the capacity of HX-2, which is to equal the latent energy released by the flue gas during condensation, should be around 16 times that of the capacity of the 
desorber, which is equal to the sensible energy released if its temperature changes from $150^{\circ} \mathrm{C}$ to $55^{\circ} \mathrm{C}$. Obviously, this would render the process impossible unless different amounts of the flue gas pass through the HX-2 and the desorber of the AHP. Therefore, a large portion of the flue gas exiting HX-1 has to be directly exhausted and only a small portion can be recovered its latent energy, as indicated by the horizontal dashed arrow between HX-1 and HX-2 in Figure1. The quantified energy balance for the exhaust gas-driven HRAHP can be found in the results section of this paper.

To evaluate the thermal efficiency improvement of the boiler due to the HRAHP, the thermal efficiency of the overall integrated HRAHP system was used. Overall thermal efficiency is defined as the ratio of the heating energy produced and the energy inputs, as shown in Equation 1. For natural gas-driven HRAHP, the energy inputs would include the natural gas used by both the boiler and the AHP. For flue gas and hot water-driven HRAHPs, the energy input is only the natural gas used by the boiler. The heating energy produced is proportional to the flow rate of the hot water and the temperature difference between the hot water return and the supply in the integrated HRAHP system.

$$
\eta_{\text {overall }}=\frac{\dot{Q}_{h w}}{\dot{Q}_{\text {input }}}=\frac{\dot{m}_{h w^{*}} C_{p_{h w}} *\left(T_{h w s}-T_{h w r}\right)}{\frac{\text { Cap }}{\text { boiler }}+\dot{Q}_{\text {add }}} \quad \text { Equation } 1
$$

\section{Modeling}

In order to provide a quantified performance evaluation for the HRAHPs, a 2-tons/hr or $1400 \mathrm{~kW}$ hot water natural gas boiler was used as the base case in the study. The models for the natural gas boiler, the AHPs, and the integrated HRAHP system were developed and illustrated as follows.

\subsection{Combustion model for natural gas boiler in EES}

The combustion in the natural gas boiler was modeled in EES, which was developed by the University of Wisconsin. EES is a general equation-solving program that can numerically solve thousands of coupled non-linear algebraic and differential equations based upon the high accuracy thermodynamic and transport property database for hundreds of substances. 
During the combustion in a natural gas boiler, the natural gas, methane, and $\mathrm{CH}_{4}$ react with the oxygen in the air, and the products from the reaction are $\mathrm{CO}_{2}, \mathrm{~N}_{2}$, and $\mathrm{H}_{2} \mathrm{O}$ along with a large amount of heat. It is common practice to use more air than the stoichiometric or theoretical amount in order to increase the chances of complete combustion or controlling the temperature of the combustion chamber. The amount of air in excess of the stoichiometric amount, often called the excess air, is usually expressed as the percent excess air, $\alpha$, in terms of the stoichiometric air. For a given percent of excess air, the reaction of natural gas combustion can be presented as shown in Equation 2.

$$
\mathrm{CH}_{4}+2(1+\alpha)\left(\mathrm{O}_{2}+3.76 \mathrm{~N}_{2}\right) \rightarrow \mathrm{CO}_{2}+2 \mathrm{HO}_{2}+7.52(1+\alpha) \mathrm{N}_{2}+2 \alpha \mathrm{O}_{2}
$$

Equation 2

The model used $20 \%$ as the percent of excess air in the study to demonstrate the performance of HRAHP. The boiler efficiency is typically defined as the ratio of the energy output of the boiler and the heat input released during fuel combustion. The heat input released during fuel combustion is mostly the higher heating value (HHV) of natural gas, which is determined by restoring all the products of combustion to the original pre-combustion temperature of $25^{\circ} \mathrm{C}$.

The indirect method is generally used in practice to determine boiler efficiency and is estimated by summing the losses and comparing them with the heat input. The major heat losses from a boiler include 1) dry flue gas leaving the stack, 2) moisture in the flue gas, 3) moisture in the combustion air, 4) radiation from the boiler surface, 5) blow down water, and 6) other loss. In the study, the losses due to 4 , 5 , and 6 above are assumed as the constants of 0.015, 0.04, and 0.005 in the boiler combustion model, respectively [22]. The other losses are estimated on the basis of the thermodynamics and heat transfer characteristics of the products of combustion, namely water vapor. Combustion always occurs at elevated temperatures so that all the products of combustion, including the water vapor, behave as ideal gases. Therefore, the products of the combustion can be treated as a gas-vapor mixture. The dew-point of a gasvapor mixture equals the saturation temperature of the water vapor at its partial pressure in the mixture according to Dalton Law of partial pressure and ideal gas properties. The partial pressure of the water vapor in the product mixture of the combustion was first calculated in the model, and then the dew-point 
temperature of the gas-vapor mixture was identified according to the partial pressure. Given the dewpoint temperature of the gas-vapor mixture, both the sensible and latent energy contained in the flue gas could be determined. Thus, the losses due to 1, 2, and 3 could be determined. Therefore, the boiler efficiency of a natural gas boiler can be calculated by using Equation 3. According to this definition, the model was able to predict the boiler thermal efficiency and was further used to compare the thermal efficiency improvement due to HRAHP.

\section{$\eta_{\text {boiler }}=1-\eta_{\text {df }}-\eta_{\text {vapor } f g}-\eta_{\text {airmoisture } f g}-\eta_{\text {radiation }}-\eta_{\text {blowdown }}-\eta_{\text {others }}$ Equation 3}

\subsection{AHP modeling}

After the combustion model of the natural gas boiler was completed, the AHPs models for the three different AHPs were developed in ABSIM. ABSIM contains the subroutines for the basic 12 component units present in absorption systems, which were developed according to energy balance, mass conservation, heat and mass transfer, and thermodynamic equilibrium. ABSIM is a proven useful platform for system performance evaluation to investigate various cycle configurations, including single-, double-, and triple-stage absorption chillers, heat pumps, and heat transformers using different working fluids such as $\mathrm{LiBr}-\mathrm{H}_{2} \mathrm{O}, \mathrm{H}_{2} \mathrm{ONH}_{3}, \mathrm{LiBr} / \mathrm{H}_{2} \mathrm{O}-\mathrm{NH}_{3}, \mathrm{LiBr} / \mathrm{ZnBr}_{2}-\mathrm{CH}_{3} \mathrm{OH}$, and others [21] .

Since the focus of this study is the integration of the natural gas boiler and the AHP, we selected singleeffect AHPs for the system design and analysis to keep the scenario simple. If the new HRAHP systems based upon single-effect AHPs can achieve a good performance, the HRAHP based on a double-effect AHP with higher efficiency could achieve better performance.

The three types of AHPs possibly used in the HRAHPs modeled are single-effect LiBr AHPs. The exhaust gas-driven AHP model used the flue gas at $150{ }^{\circ} \mathrm{C}$ as the heat input to the desorber. The directfired AHP was modeled as an AHP driven by the flue gas at $250-350^{\circ} \mathrm{C}$, which simulates the hot gas mixture in the combustion chamber embedded in the desorber of the AHP. The hot water-driven AHP model used the $98^{\circ} \mathrm{C}$ hot water produced by a natural gas boiler. 
The inputs of the AHP models, shown in Figure 2, include the temperature and the flow for the hot water returns, the thermal resources, and the chilled water supply from the evaporator; the qualities of the refrigerant coming from the desorber and the evaporator; and the effectiveness of all the heat exchangers including the evaporator, the absorber, the condenser, the desorber, and the heat exchanger between the absorber and the desorber. The hot water return was assumed to be $45^{\circ} \mathrm{C}$ and $8 \mathrm{~kg} / \mathrm{s}$, and the refrigerant from the desorber and the evaporator was assumed to be pure water vapor, which means the quality of the refrigerant equals 1 . The thermal inputs for the exhaust gas-driven, hot water-driven, and direct-fired AHPs assumed in the models are flue gas at $150^{\circ} \mathrm{C}$ and $0.69 \mathrm{~kg} / \mathrm{s}$, hot water at $98^{\circ} \mathrm{C}$ and $8 \mathrm{~kg} / \mathrm{s}$, and flue gas at $250^{\circ} \mathrm{C}$ and $1.2 \mathrm{~kg} / \mathrm{s}$, respectively.

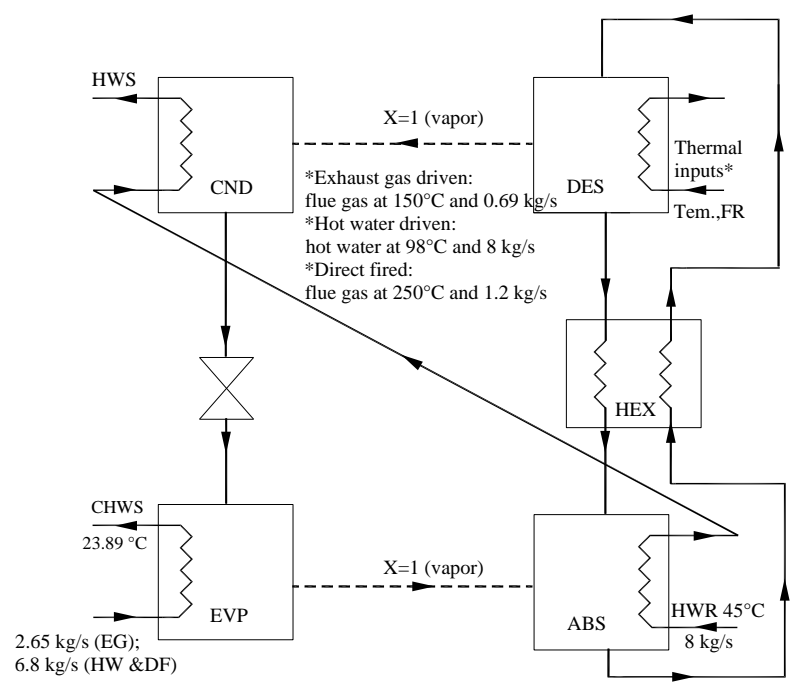

\section{Figure 2 inputs for the AHP models}

The governing equations applied to each of the components were formed from the following: conservation of mass, energy balance, heat transfer by using the effectiveness method, and vapor pressure-temperature-concentration equilibrium between the liquid and the vapor. From these equations for each component, a set of nonlinear equations was formed for the entire system and were solved simultaneously. After the models were converged, the AHP models were able to predict the working conditions and system performance, such as the COP, the heat capacity, and the overall heat transfer coefficient UA, heat transfer effectiveness (EFF), and log mean temperature difference (LMTD) for the 
key components of the AHPs. The performance predicted by the three AHP models was used in the overall HRAHP models.

\subsection{Overall Model of the HRAHPs}

The overall system models for the different HRAHPs were developed in EES. The overall HRAHP models integrated the boiler combustion model and the predicted performance of the AHP, plus the models for HX-1 and HX-2, which were developed according to mass conservation, energy balance, and heat transfer by using the effectiveness method. The overall system HRAHP models were able to predict the overall system efficiencies and the system working conditions. The results of the related models are detailed in the following section.

\section{Model Results and Predicted Performance}

\subsection{Boiler efficiency}

The results from the boiler model show the relationship between boiler efficiency and the temperatures of the flue gas exiting the boiler. As shown in Figure 3, boiler efficiency increased with a reduction of the flue gas temperature for all six different excess air ratios ranging from 0 to 1 . For the same temperature of flue gas, the more excess air that was provided, the lower was the boiler efficiency because more excess air carries more heat out of the combustion chamber without involving combustion. In addition, two different correlation regimes were identified with an inflection point on each of the six boiler efficiency curves. The inflection points were actually the efficiencies at the dew point of the flue gas. The boiler efficiency improvement rate was much higher when the flue gas exited at lower temperatures than the dew point of the flue gas. This significant increase in boiler efficiency was due to the large amount of latent energy produced by the water vapor when it was condensed. Furthermore, since the dew point of the flue gas decreased when the excess air increased, the inflection point shifted toward lower temperatures along with the changes in the dew points. 


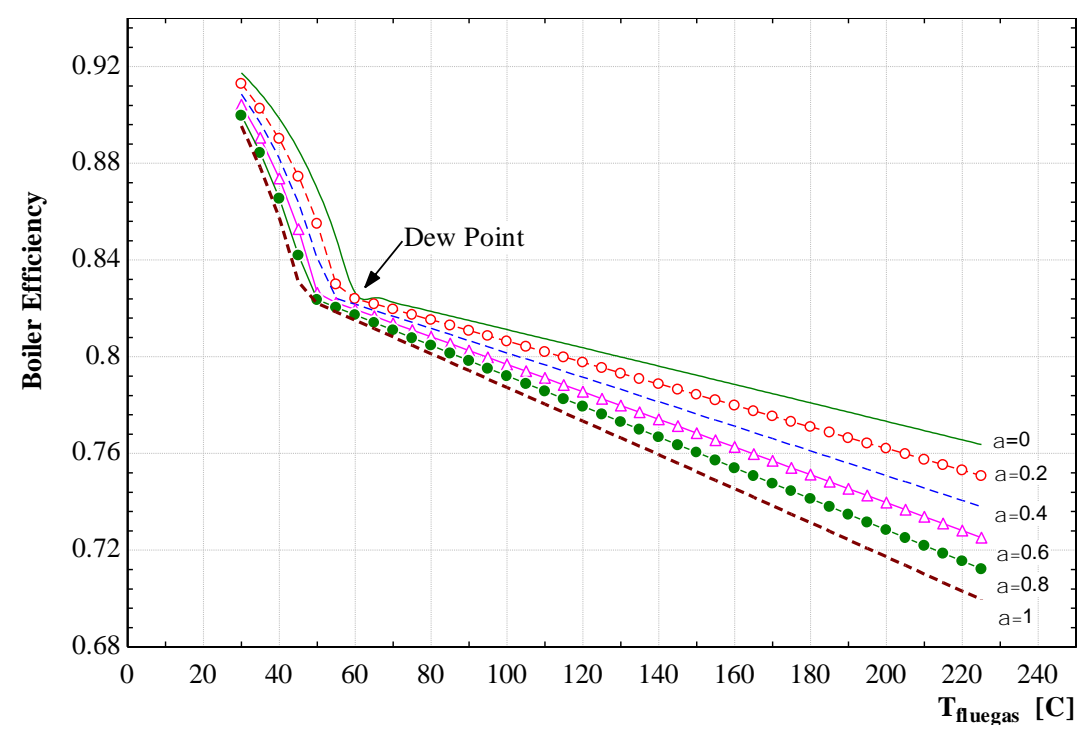

Figure 3 Boiler efficiency at various excess air ratios and flue gas temperatures

Based on the predictions of the boiler combustion model, the thermal efficiency of the $1400 \mathrm{~kW}$ hot water natural gas boiler, the base case, was $78.4 \%$, where the excess air was $20 \%$ and the flue gas exiting from the boiler was at $150^{\circ} \mathrm{C}$. The assumptions and thermal performance of the $1400 \mathrm{~kW}$ hot water natural gas boiler were also used for the performance comparison between the base case and the HRAHPs.

Figure 3 indicates that the dew point of the flue gas was at the range of $40{ }^{\circ} \mathrm{C}$ to $60{ }^{\circ} \mathrm{C}$, the heating water return used for condensing the flue gas in condensing boiler is around at the similar range. This explains why the efficiency improvement by the condensing boilers was very limited. However, AHP can recover the latent energy in the flue gas by working with the two heat exchangers together in the HRAHPs.

\subsection{The performance of the HRAHPs}

The overall system HRAHP models predicted the system performance and thermal efficiency improvement of the natural gas boilers due to the three types of HRAHPs.

\subsubsection{The performance of the exhaust gas driven HRAHP}

As indicated in Figure 4, the flue gas from the boiler, as the thermal input, first flowed through the desorber and then passed through HX-1 and HX-2. The hot water return flowed through the absorber, the condenser, HX-1, and the boilers in sequence. As mentioned previously, the amount of flue gas that 
passes through $\mathrm{HX}-2$, and $\mathrm{HX}-1$ and the absorber are different. According to the energy balance and performance analysis, the whole stream of the flue gas would pass the desorber to drive the absorption heat pump and then flow through HX-1 to heat the hot water returns coming from the AHP; and only $23 \%$ of the flue gas will pass HX-2 and condense by using the chilled water from the AHP and the remaining $77 \%$ of the flue gas will be directly released to the atmosphere after HX-1. For the base case of a 1400 $\mathrm{kW}$ boiler, the exhaust gas HRAHP can heat the hot water return at $8 \mathrm{~kg} / \mathrm{s}$ from $45^{\circ} \mathrm{C}$ to $89.7^{\circ} \mathrm{C}$. The overall system efficiency, calculated by using Equation 1, is $83.9 \%$ (5.5\% improvement) compared to $78.4 \%$ of the thermal efficiency for the base case boiler.

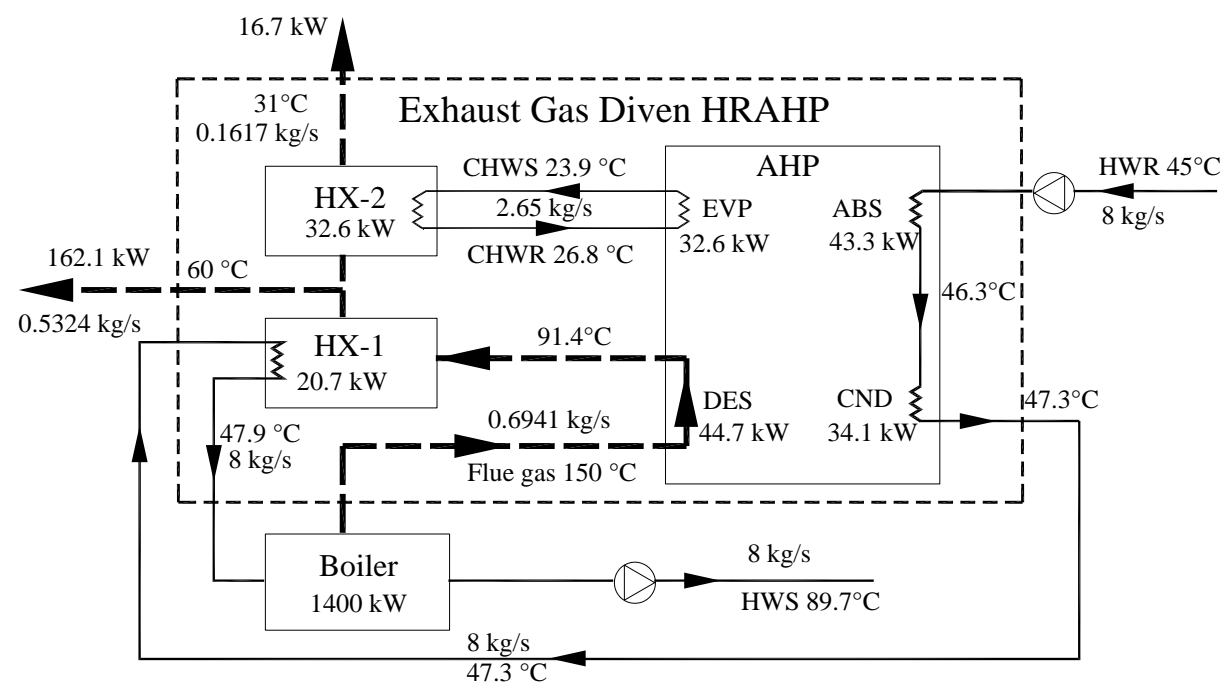

Figure 4 Schematic system diagram of the exhaust gas driven HRAHP

The system performance and characteristics of the exhaust gas-driven HRAHP at the component level is detailed in Table 1, which summarizes the heat transfer coefficient UA, EFF, and LMTD, and the heat transfer rate of the key components in the HRAHP.

Table 1 Characteristics of the key components of the exhaust gas-driven HRAHP

\begin{tabular}{|c|l|c|c|c|c|}
\hline NO. & \multicolumn{1}{|c|}{ TYPE } & UA $\left(\mathbf{k W} /{ }^{\circ} \mathbf{C}\right)$ & $\mathbf{E F F}$ & LMTD $\left.\mathbf{~}^{\mathbf{0}} \mathbf{C}\right)$ & $\begin{array}{c}\text { HEAT TRANSFER } \\
(\mathbf{k W})\end{array}$ \\
\hline $\mathbf{1}$ & EVAPORATOR & 15.33 & 0.75 & 2.12 & 32.56 \\
\hline $\mathbf{2}$ & HEAT EXGER & 2.26 & 0.72 & 9.03 & 20.43 \\
\hline $\mathbf{3}$ & DESORBER & 1.28 & 0.80 & 35.05 & 44.74 \\
\hline $\mathbf{4}$ & CONDENSER & 49.14 & 0.77 & 0.69 & 34.05 \\
\hline $\mathbf{5}$ & ABSORBER & 6.73 & 0.36 & 6.43 & 43.25 \\
\hline $\mathbf{6}$ & HX-1 & 0.83 & 0.85 & 25.00 & 20.65 \\
\hline $\mathbf{7}$ & HX-2 & 1.92 & 0.90 & 16.92 & 32.56 \\
\hline
\end{tabular}


The model demonstrated that the exhaust gas-driven AHP is able to produce $32.6 \mathrm{~kW}$ of the cooling for recovering the latent energy in the HX-2 and add $77.4 \mathrm{~kW}$ of the heat to the hot water return by using $44.7 \mathrm{~kW}$ of the flue gas at $150^{\circ} \mathrm{C}$ as the thermal resource for the AHP. The COP of the exhaust gas AHP is 1.73 for heating and 0.73 for cooling. Overall, the energy ratio of the evaporator of the AHP to the boiler capacity is $1 / 43$ and the improvement of the boiler efficiency is $5.5 \%$. The improvement of the boiler efficiency is not significant and roughly equal to the improvement of a condensing boiler. Therefore the decision of using the flue gas driven HRAHP should be carefully made by taking consideration of life cycle economic benefits.

\subsubsection{The performance of the hot water-driven HRAHP}

The hot water from the boiler at $98^{\circ} \mathrm{C}$ is used as the heat resource for the AHP in the hot water-driven HRAHP. Figure 5 illustrates the configuration and system performance of the hot water-driven HRAHP according to the model results. In this configuration, HX-1 and HX-2 recover the flue gas sequentially.

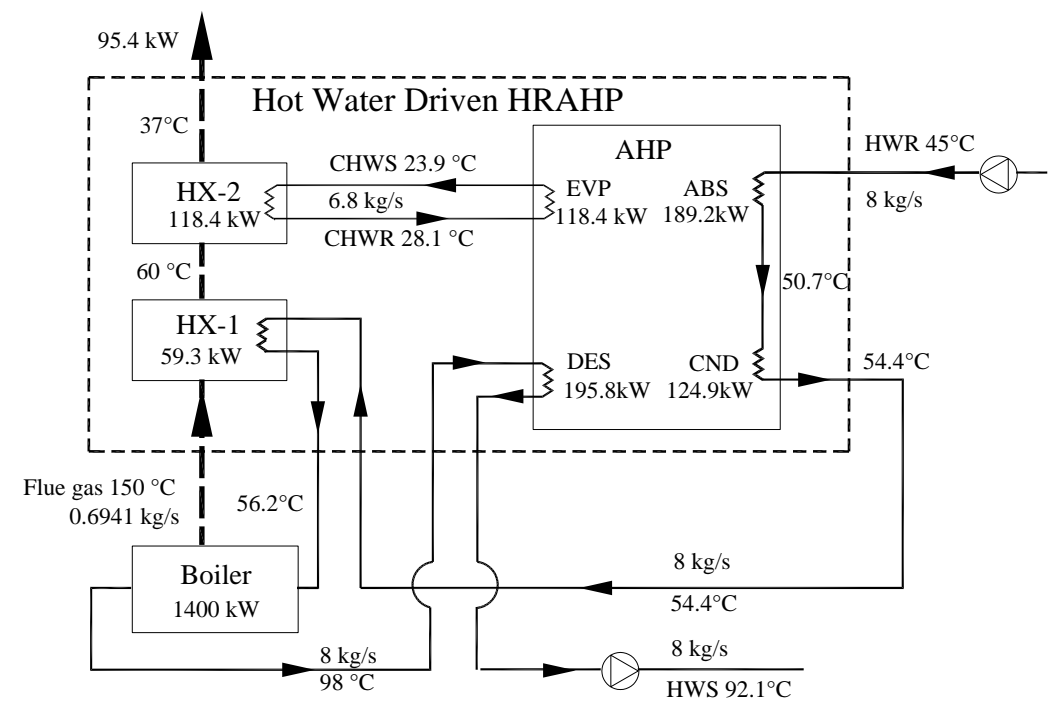

Figure 5 Schematic system diagram for the hot water-driven HRAHP

The latent energy of the flue gas recovered by HX-2 is about twice of the sensible energy in the flue gas recovered in HX-1. According to the model results, for the base case $1400 \mathrm{~kW}$ boiler, the hot waterdriven HRAHP can heat the hot water return at $8 \mathrm{~kg} / \mathrm{s}$ from $45^{\circ} \mathrm{C}$ to $92.1^{\circ} \mathrm{C}$. The overall system efficiency was calculated as $88.4 \%$, which was a $10 \%$ improvement from the $78.4 \%$ thermal efficiency in the base 
case. Table 2 summarizes the system performance and characteristics of the key components, including the heat transfer coefficient UA, EFF, and LMTD and the heat transfer rate in the hot water-driven HRAHP.

Table 2 Characteristics of the key components of the hot water driven HRAHP

\begin{tabular}{|c|l|c|c|c|c|}
\hline NO. & \multicolumn{1}{|c|}{ TYPE } & UA $\left(\mathbf{k W} /{ }^{\circ} \mathbf{C}\right)$ & $\mathbf{E F F}$ & LMTD $\left({ }^{\mathbf{}} \mathbf{C}\right)$ & $\begin{array}{c}\text { HEAT TRANSFER } \\
(\mathbf{k W})\end{array}$ \\
\hline $\mathbf{1}$ & EVAPORATOR & 38.31 & 0.74 & 3.09 & 118.37 \\
\hline $\mathbf{2}$ & HEAT EXGER & 10.38 & 0.69 & 12.70 & 131.78 \\
\hline $\mathbf{3}$ & DESORBER & 41.60 & 0.60 & 4.71 & 195.82 \\
\hline $\mathbf{4}$ & CONDENSER & 49.16 & 0.77 & 2.54 & 124.95 \\
\hline $\mathbf{5}$ & ABSORBER & 31.30 & 0.53 & 6.05 & 189.24 \\
\hline $\mathbf{6}$ & HX-1 & 1.89 & 0.85 & 31.30 & 59.26 \\
\hline $\mathbf{7}$ & HX-2 & 5.58 & 0.90 & 21.22 & 118.40 \\
\hline
\end{tabular}

The hot water driven-AHP is able to produce $118.4 \mathrm{~kW}$ of the cooling to recover the latent energy in the HX-2 and add $314.2 \mathrm{~kW}$ of the heat to hot water return by using $44.7 \mathrm{~kW}$ flue gas at $150^{\circ} \mathrm{C}$ as the thermal resource to drive the AHP. The COP of hot water-driven AHP is 1.60 for heating and 0.6 for cooling. The evaporator capacity of the AHP is approximate $1 / 12$ of the boiler capacity and the improvement of the boiler efficiency is $10 \%$.

\subsubsection{Direct fired HRAHP}

With the exception of the desorber heat source, the direct fired HRAHP has similar system configuration to the hot water HRAHP. Since the heat resource is natural gas rather than hot water, the hot water loop is arranged differently, as shown in Figure 6.

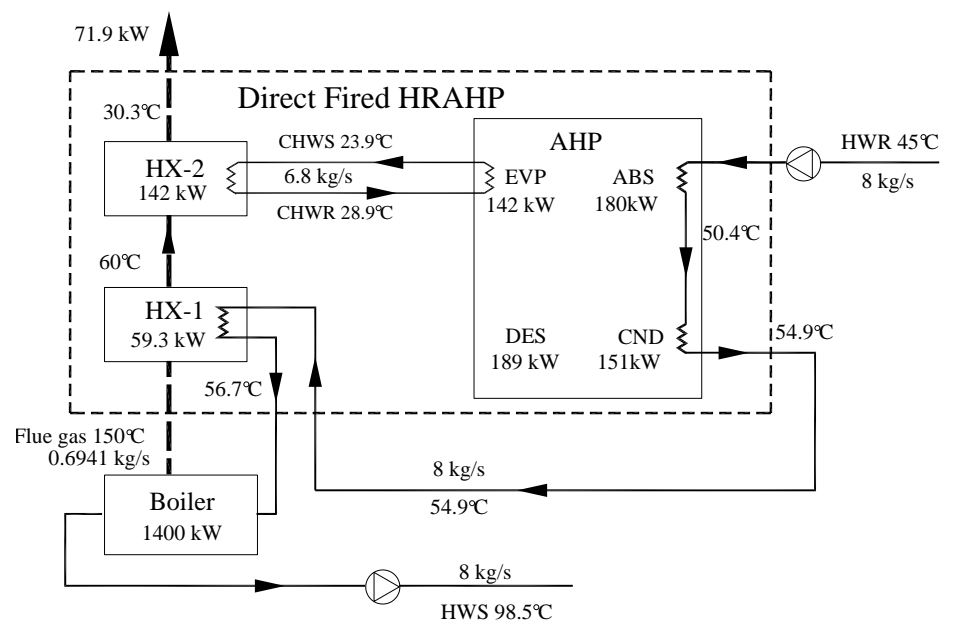

Figure 6 Schematic system diagram for the direct-fired HRAHP 
The natural gas burner of the AHP was assumed to have a thermal efficiency at $78.4 \%$, which is the same as the boiler in the base case. According to the model predictions, for the base case of the $1400 \mathrm{~kW}$ boiler, the direct-fired HRAHP can heat the hot water return at $8 \mathrm{~kg} / \mathrm{s}$ from $45^{\circ} \mathrm{C}$ to $98.5^{\circ} \mathrm{C}$. The overall efficiency of this system configuration is predicted to be $88.4 \%$, which is a $10 \%$ improvement of the $78.4 \%$ efficiency of the boiler in the base case, but with an additional $242.3 \mathrm{~kW}$ consumption of natural gas. Table 3 summarizes the system performance and characteristics of the key components, including the heat transfer coefficient UA, EFF, LMTD, and the heat transfer rate in the direct-fired HRAHP. The COP of the direct-fired AHP was 1.75 for heating and 0.75 for cooling. The evaporator capacity of the AHP was approximately $1 / 10$ of the boiler capacity and the improvement of the boiler efficiency was $10 \%$. The capacity of HX-2 or the evaporator of AHP was more than four times that of the exhaust gas HRAHP. The improvement of thermal efficiency in the direct-fired HRAHP was similar to the hot water-driven HRAHP.

Table 3 Characteristics of the key components of the direct-fired HRAHP

\begin{tabular}{|c|l|c|c|c|c|}
\hline NO. & \multicolumn{1}{|c|}{ TYPE } & UA $\left(\mathbf{k W} /{ }^{\circ} \mathbf{C}\right)$ & EFF & LMTD $\left({ }^{\mathbf{}} \mathbf{C}\right)$ & $\begin{array}{c}\text { HEAT TRANSFER } \\
(\mathbf{k W})\end{array}$ \\
\hline $\mathbf{1}$ & EVAPORATOR & 39.40 & 0.75 & 3.60 & 142.00 \\
\hline $\mathbf{2}$ & HEAT EXGER & 3.43 & 0.72 & 15.30 & 52.70 \\
\hline $\mathbf{3}$ & DESORBER & 2.46 & 0.79 & 77.20 & 190.00 \\
\hline $\mathbf{4}$ & CONDENSER & 49.20 & 0.77 & 3.07 & 151.00 \\
\hline $\mathbf{5}$ & ABSORBER & 17.20 & 0.50 & 10.50 & 181.00 \\
\hline $\mathbf{6}$ & HX-1 & 1.95 & 0.85 & 30.30 & 59.26 \\
\hline $\mathbf{7}$ & HX-2 & 9.11 & 0.90 & 15.58 & 142.00 \\
\hline
\end{tabular}

\subsubsection{Overall System Evaluation}

Seven parameters served as the indicators for system performance to compare the three differently configured HRAHPs in Table 4. The hot water-driven and the direct fired HRAHP achieved the highest overall system efficiency at $88.4 \%$. The capacity of HX-2 or the evaporator of the AHP required for the exhaust gas-driven HRAHP was $23 \%$ of the capacity in the hot water-driven or the direct-fired HRAHPs.

Table 4 Summary of the performance of the three HRAHPs

\begin{tabular}{|l|c|c|c|c|c|c|c|}
\hline \multicolumn{1}{|c|}{ Type } & $\begin{array}{c}\text { AHP's COP } \\
\text { for heating }\end{array}$ & $\begin{array}{c}\text { Required AHP's } \\
\text { capacity ( kW) }\end{array}$ & $\begin{array}{c}\text { Energy in flue gas } \\
\text { recovered ( kW) }\end{array}$ & $\begin{array}{c}\text { Heating provided by } \\
\text { the HRAHP }(\mathbf{k W})\end{array}$ & $\begin{array}{c}\text { Energy input of } \\
\text { the HRAHP }(\mathbf{k W})\end{array}$ & $\begin{array}{c}\text { Overall } \\
\text { efficiency }\end{array}$ & $\begin{array}{c}\text { Improvement of } \\
\text { boiler efficiency }\end{array}$ \\
\hline Exhaust gas & 1.73 & 33 & 98 & 1498 & 1786 & $83.9 \%$ & $5.5 \%$ \\
\hline Hot water & 1.60 & 118 & 178 & 1579 & 1786 & $88.4 \%$ & $10.0 \%$ \\
\hline Direct fired & 1.75 & 142 & 201 & 1793 & 2028 & $88.4 \%$ & $10.0 \%$ \\
\hline
\end{tabular}


The three alternatives provide multiple choices for users considering their economic and energy performance, which enhances the potential for market penetration of the HRAHPs.

\section{Experiments and Model Validation}

The experiments were focused on the tests at the equipment level due to the limited research resources and the stage of the technology. We designed the experiments aiming to validate the feasibility of the working conditions of the equipment predicted by the related models. A hot water-driven absorption heat pump was tested as it was the only available equipment during the study. We used a water-cooled hot water-driven $\mathrm{LiBr}$ absorption chiller and operated it as a heat pump. Due to the limited availability of the absorption chiller, we used the absorption chiller with a cooling capacity of $70 \mathrm{~kW}$, which is approximately half of the capacity of the absorption heat pump used in the models of the HRHAPs. The $\mathrm{LiBr}$ absorption chiller is a single-effect machine with a parallel flow configuration as shown in Figure 7. The sensors for measuring the temperatures and the flow rates of different working fluids were installed and acquired the data during the tests, as indicated in Figure 8. The measured working fluids included chilled water, heat resource water, hot water, and $\mathrm{LiBr}$ solution in the absorption heat pump.

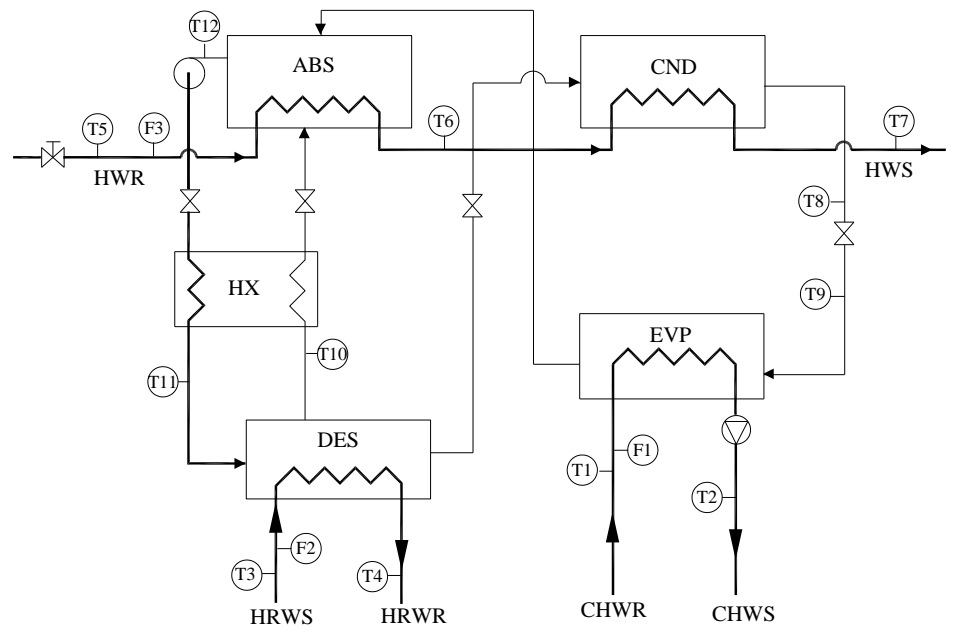

\section{Figure 7 The test program of a hot-water driven absorption heat pump for HRAHP}

The absorption heat pump was tested at 12 working conditions, in which four parameters were varied for the performance evaluation. The four parameters were the flow rate, F3, of the hot water (HW) at the 
range of $0.6-1.3 \mathrm{~kg} / \mathrm{s}$; the chilled water return (CWR) temperature, $\mathrm{T} 1$, varying from $30^{\circ} \mathrm{C}$ to $40^{\circ} \mathrm{C}$; the temperature, T3, of the heat resource water supply (HRWS) varying from $95^{\circ} \mathrm{C}$ to $100^{\circ} \mathrm{C}$; and the hot water return temperature (HWR), T5, varying from $43^{\circ} \mathrm{C}$ to $50^{\circ} \mathrm{C}$. Only one parameter of the four was changed and the others were kept constant in one test setting. Based on the experimental data, the average heating capacity of the tested AHP was $72 \mathrm{~kW}$ with a heating COP of 1.29. In addition, the experimental data showed that both the heat capacity and the COP of the AHP decreased with increases in the temperature of the hot water return, as shown in Figure 8.

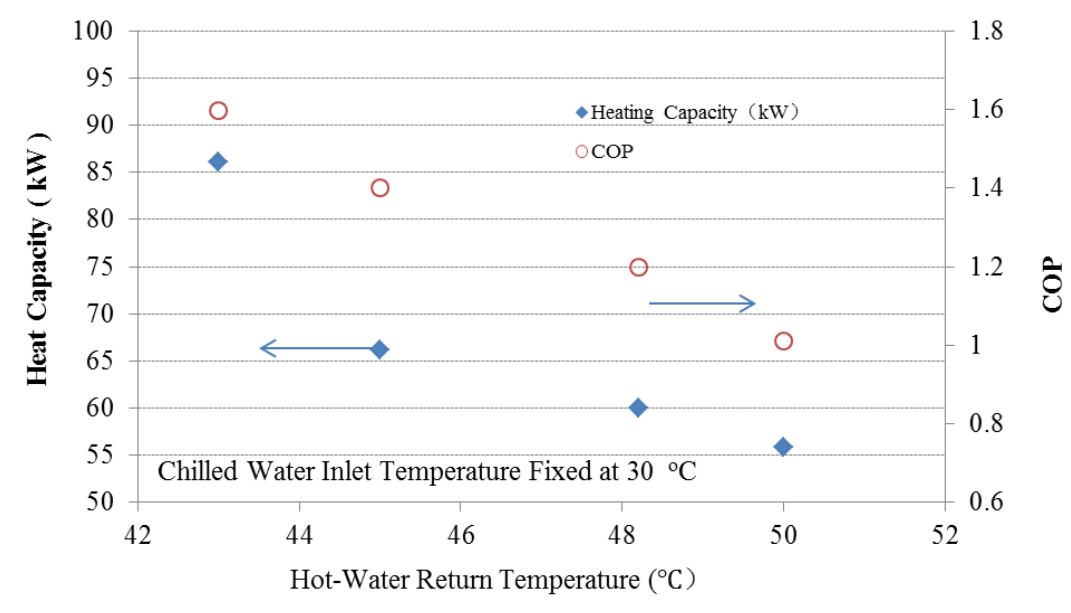

Figure 8 Heat capacity and COP vs. hot water return temperature

Since the tested AHP had different characteristics of the components from the AHP models used for the study of HRAHP, a new AHP model was developed in ABSIM according to the tested AHP; and the same method used for the AHP models in the HRAHPs for the model validation. Among the 12 experiments, one test data set was used for model validation. Table 5 shows the comparison between the experimental data and the model results predicted by the ABSIM model. The sensor names are indicated in Figure7. In the calculation results columns, the parameters in italics and bold typeface are inputs and the others are the calculation outputs. Table 5 shows that the experimental data were in agreement with the performance predicted by the AHP model. Table 6 details the characteristics of the tested AHP based on the model calculation results. The agreement shown in Table 6 verified the AHP model for the tested machine. Furthermore the feasibility study of the HRAHP was also confirmed since, except for specified 
characteristics parameters, the same modeling method and cycle configurations were used for the models of the tested AHP and the three AHPs used in HRAHPs.

Table 5 Testing results of the absorption heat pump

\begin{tabular}{|c|c|c|c|c|}
\hline \multicolumn{5}{|c|}{ A Single-Effect Hot-Water Driven Absorption Heat Pump } \\
\hline & & Unit & $\begin{array}{c}\text { Experimental } \\
\text { Data }\end{array}$ & $\begin{array}{c}\text { Calculation } \\
\text { Results }\end{array}$ \\
\hline \multicolumn{5}{|c|}{ Flow Rate } \\
\hline F1 & Chilled Water (CHW) Flow Rate & $\mathrm{kg} / \mathrm{s}$ & 3.8 & 3.8 \\
\hline F2 & Heat Resource Water (HRW) Flow Rate & $\mathrm{kg} / \mathrm{s}$ & 2.6 & 2.6 \\
\hline F3 & Hot Water (HW) Flow Rate & $\mathrm{kg} / \mathrm{s}$ & 1.3 & 1.3 \\
\hline \multicolumn{2}{|r|}{ Temperature } & ${ }^{\circ}$ & & \\
\hline $\mathrm{T} 1$ & CHW Return Temperature & ${ }^{\circ} \mathrm{C}$ & 30.0 & 30.0 \\
\hline $\mathrm{T} 2$ & CHW Supply Temperature & ${ }^{\circ} \mathrm{C}$ & 28.5 & 28.8 \\
\hline $\mathrm{T} 3$ & HRW Inlet Temperature & $\circ$ & 95.8 & 95.8 \\
\hline $\mathrm{T} 4$ & HRW Outlet Temperature & ${ }^{\circ} \mathrm{C}$ & 91.5 & 91.6 \\
\hline $\mathrm{T} 5$ & HW Return Temperature & ${ }^{\circ} \mathrm{C}$ & 45.0 & 45.0 \\
\hline T6 & HW Temperature after the Absorber & & 51.5 & 53.5 \\
\hline $\mathrm{T} 7$ & HW Supply Temperature & of & 57.5 & 57.5 \\
\hline \multicolumn{2}{|r|}{ Performance } & ${ }^{\circ} \mathrm{C}$ & & \\
\hline T_HRW & HRW Temperature Difference & & 4.3 & 4.2 \\
\hline T_HW & HW Temperature Difference & & 12.5 & 12.5 \\
\hline Q_HRW & Thermal Energy Input & $\mathrm{kW}$ & 46.9 & 45.9 \\
\hline Q_HW & Heating Power Generation & $\mathrm{kW}$ & 66.2 & 66.2 \\
\hline $\mathrm{COPh}$ & Coefficient of Performance (COP) for Heating & & 1.4 & 1.4 \\
\hline
\end{tabular}

Table 6 Characteristics of the key components of the hot water-driven AHP estimated by ABSIM model

\begin{tabular}{|c|c|c|c|c|c|c|c|}
\hline NO. & TYPE & UA $\left(\mathbf{k W} /{ }^{\circ} \mathbf{C}\right)$ & NTU & EFF & CAT $\left({ }^{0} \mathbf{C}\right)$ & LMTD $\left({ }^{0} \mathbf{C}\right)$ & $\begin{array}{c}\text { HEAT TRANSFER } \\
(\mathbf{k W})\end{array}$ \\
\hline $\mathbf{1}$ & EVAPORATOR & 11.00 & 0.70 & 0.50 & 1.20 & 1.79 & 20 \\
\hline $\mathbf{2}$ & HEAT EXGER & 0.70 & 0.66 & 0.40 & 22.20 & 22.30 & 16 \\
\hline $\mathbf{3}$ & DESORBER & 25.60 & 2.34 & 0.70 & 1.80 & 1.80 & 46 \\
\hline $\mathbf{4}$ & CONDENSER & 8.00 & 1.51 & 0.78 & 1.12 & 2.62 & 21 \\
\hline $\mathbf{5}$ & ABSORBER & 4.86 & 0.92 & 0.55 & 7.00 & 9.27 & 45 \\
\hline
\end{tabular}

\section{Simple Economic Analysis for HRAHPs}

To predict the economic performance of the HRAHPs, a 53,628 $\mathrm{ft}^{2}$ commercial building in Philadelphia, Pennsylvania that was defined by the U.S. Department of Energy (DOE) Commercial Reference Building Models, was used as an example to perform an economic evaluation [23 and 24]. The building heating was provided by a natural gas-fired boiler with a capacity of $250 \mathrm{~kW}$. According to the hourly heating load predicted by the DOE building model, Approximately 6,114 hours of heating were required in a range of 0 to $115 \%$ of the rated capacity of the boiler from October to April. The first cost added due to a HRAHP included an AHP and two heat exchangers. According to the market price of absorption chillers, 
the cost of AHPs was estimated as $\$ 400 / \mathrm{kW}$ [27], and the cost for the heat exchangers was $\$ 30 / \mathrm{kW}$ [28]. The installation cost is typically estimated as 1.3 times of the first cost of a system according to the RS Means cost guide [30]. During the operational periods, the power consumed by the pumps embedded in an AHP is approximately $1 \mathrm{~kW}$ for capacities in the range of $16-32 \mathrm{~kW}$ and $1.8 \mathrm{~kW}$ for capacities of more than $32 \mathrm{~kW}$ [5]. The only maintenance action needed for the AHPs relates to the vacuum pump of the desorber of the AHP every two months, which is a task that an average mechanical technician will be able to accomplish as long as the vacuum pump is available. The estimated cost for the vacuum was $\$ 50 /$ year for small capacity and $\$ 100 /$ year for a relatively large capacity. The vacuum pump cost was estimated at approximately $\$ 750$. The annual savings due to the HRAHPs were calculated according to the total amount of electricity and natural gas saved. The natural gas price was assumed at $\$ 1.3 /$ therm or $\$ 0.044 / \mathrm{kWh}[25]$, and the electricity rate was assumed at $\$ 0.0897 / \mathrm{kWh}$ [26]. Given the initial cost, the annual operating cost, and the annual savings, the cost of the investment and the annual net savings could be calculated. Table 7 shows the predicted performance if HRAHPs are applied to the reference building.

Table 7 Economic performance prediction for the HRAHPs

\begin{tabular}{|c|c|c|c|c|c|c|c|c|}
\hline Type & $\begin{array}{l}\text { Required AHP's } \\
\text { capacity ( kW })\end{array}$ & $\begin{array}{l}\text { Heat Exchanger } \\
\text { capacity }(\mathbf{k W})\end{array}$ & $\begin{array}{l}\text { Improvement of } \\
\text { boiler efficiency }\end{array}$ & $\begin{array}{c}\text { Annual NG } \\
\text { savings (therm) }\end{array}$ & $\begin{array}{c}\text { First cost added } \\
\text { (equipment + } \\
\text { installation) }\end{array}$ & $\begin{array}{l}\text { Annual } O \\
\& M \text { cost }\end{array}$ & $\begin{array}{l}\text { Annual } \\
\text { savings }\end{array}$ & $\begin{array}{c}\text { Simple } \\
\text { payback year }\end{array}$ \\
\hline Exhaust gas & 33 & 10 & $5.5 \%$ & 7994 & $\$ 18,278$ & $\$ 462$ & $\$ 10,392$ & 1.8 \\
\hline Hot water & 118 & 32 & $10.0 \%$ & 14581 & $\$ 56,070$ & $\$ 594$ & $\$ 18,955$ & 3.1 \\
\hline Direct fired & 142 & 36 & $10.0 \%$ & 14600 & $\$ 66,987$ & $\$ 594$ & $\$ 18,980$ & 3.6 \\
\hline
\end{tabular}

Accordingly, the simple payback years for the exhaust gas type, hot water, and direct-fired HRAHPs are 1.7, 3.1, and 3.6, respectively, for the benchmark medium size commercial building in Philadelphia, which is located in the 4A ASHRAE climate zone, a light heating dominated location. The same or even better economic performance could be achieved for heating dominated locations with HRAHPs.

\section{Conclusion and Discussions}

This paper presented a new concept of integrating absorption heat pumps with natural gas-fired boilers to improve boiler efficiency by $5-10 \%$ through waste heat recovery. This concept employs an absorption heat pump to cool natural gas boiler flue gas to ambient conditions while harvesting heating energy. 
Three potential system configurations due to the three possible thermal resources for the absorption heat pump were comprehensively designed and analyzed; and analytical models of the heat and mass transfer processes of HRAHP systems were developed to evaluate the system performance. The modeling results suggest $5-10 \%$ improvements in boiler efficiency due to using the three HRAHPs. Among the three system configurations, the hot water-driven HRAHP and the direct fired HRAHP achieved the best performance with a $10 \%$ improvement in boiler thermal efficiency over the boiler efficiency in the base case. The exhaust gas-driven HRAHP provided modest efficiency improvements, but it can be added to existing boilers and has a relatively quick payback of 1.7 years. The exhaust gas-driven HRAHP requires the smallest capacity of the AHP so that the system could be easily installed with the existing system. The hot water-driven HRAHP was predicted to have a faster payback and more annual savings although it is operated at a lower COP compared to the direct-fired HRAHP. Finally, it was concluded that the directfired HRAHP could be more favorable due to the flexibility in the system's operation and its potential for increasing overall system capacity even though it has the longest payback period.

Experiments on a hot water-driven absorption heat pump were carried out to test the performance of the absorption heat pump and to validate the corresponding AHP model. The experimental data indicated that the absorption heat pump was able to heat the hot water return from $45^{\circ} \mathrm{C}$ to $57.5^{\circ} \mathrm{C}$ by using $98^{\circ} \mathrm{C}$ hot water as the heat resource. Additionally, the experiments showed that the hotter the hot water return was, the lower were the heating capacity and the COP. The experimental data were in excellent agreement with the calculation results of the AHP model in ABSIM and confirmed the feasibility of the concepts of the HRAHPs in the three described configurations.

Regarding future applications of this HRAHP technology, it could be applied not only to natural gas boilers, but also to natural gas-based combined heating and power systems [11] to achieve benefits in the energy, environment, and economic areas. In the CHP systems, typically the flue gas from the natural gas power generator has a higher temperatures compared to the one from natural boilers. The flue gas is often used as the thermal resource to drive absorption chillers for cooling and / or the flue gas will be 
continuously used for heat recovery through heat exchangers. Similar situation, heating water return is typically used for the heat recovery. The new technology could be integrated in the CHP systems to further improve overall system efficiency.

\section{Acknowledgements}

This research was funded by the U.S. DOE Visiting Faculty Program. We thank Patricia W. Garland, Nasr E. Alkadi, Sachin U. Nimbalkar, and James R. Keiser from the Oak Ridge National Laboratory for enlightening discussions and for leveraging the authors' technical expertise during this research project.

\section{References:}

[1] D. Che, Y. Liu, and C. Gao, Evaluation of retrofitting a conventional natural gas-fired boiler into a condensing boiler. Energy Conversion and Management, 45 (2004), pp. 3251-3266.

[2] C. Weber, B. Gebhardt, and U. Fahl, Market transformation for energy efficient technologies success factors and empirical evidence for gas condensing boilers, Energy, 27 (2002), pp. 287-315.

[3] M. Searle and A.R. Shiret, The opportunities for a new generation of high-efficiency gas boilers, Gas Engineering Management 26 (7-8) (1986), pp. 200-214.

[4] P.L. Boeschen, A case study of condensing boiler energy savings. ASHRAE Transactions, 106 (2000), pp. 96-105.

[5] Broad Air Conditioning product brochure, Broad IX absorption chiller, 2004.

[6] K.C. Ng, H.T. Chua, Q. Han, T. Kashiwagi, A. Akisawa, and T. Tsurusawa, Thermodynamic modeling of absorption chiller and comparison with experiments. Heat Transfer Engineering, 20 (1999), pp. $42-51$.

[7] S. Jeong, B.H. Kang, and S.W. Karng, Dynamic simulation of an absorption heat pump for recovering low grade waste heat. Applied Thermal Engineering 18 (1998), pp.1-12.

[8] A. Costa, B. Bakhtiari, S. Schuster, and J. Paris, Integration of absorption heat pumps in a Kraft pulp process for enhanced energy efficiency, Energy 34 (2009), pp. 254-260. 
[9]X. Li, W. Wu, X. Zhang, W. Shi, and B. Wang, Energy saving potential of low temperature hot water system based on air source absorption heat pump. Applied Thermal Engineering 48, (2012), pp. 317-324.

[10] C. Keil, S. Plura, M. Radspieler, and C. Schweigler, Application of customized absorption heat pumps for utilization of low-grade heat sources, Applied Thermal Engineering 28 (2008), pp. 2070-2076.

[11] L. Fu, X. Zhao, S. Zhang, Y. Li, Y. Jiang, H. Li, and Z. Sun, Performance study of an innovative natural gas CHP system, Energy Conversion and Management 52 (2011), pp.321-328.

[12] G. Grossman, Solar-powered systems for cooling, dehumidification, and air conditioning, Solar Energy 72 (2002) 53-62.

[13]J. Sun, L. Fu, S. Zhang, and W. Hou, A mathematical model with experiments of single effect absorption heat pump using LiBr-H2O, Applied Thermal Engineering 30 (2010), pp. 2753-2762.

[14] B. Bakhtiari, L. Fradette, R. Legros, and J. Paris, A model for analysis and design of H2O- $\mathrm{LiBr}$ absorption heat pumps, Energy Conversion and Management. 52 (2011), pp. 1439-1448.

[15] J. Sun, F. L. Fu, and S. Zhang, Performance calculation of single effect absorption heat pump using bLiBr+ LiNO3 + H2O as working fluid, Applied Thermal Engineering 30 (2010) pp.2680-2684.

[16] A. Yokozeki, Theoretical performances of various refrigerant-absorbent pairs in a vapor-absorption refrigeration cycle by the use of equations of state, Applied Energy 80 (2005) 383-399.

[17] G.A. Florides, S.A. Kalogirou, S.A. Tassou, and L.C. Wrobel, Design and construction of a LiBre water absorption machine, Energy Conversion and Management 44 (2003) 2483-2508.

[18] Q. Chen, K. Finney, H. Li, X. Zhang, J. Zhou, V. Sharifi, and J. Swithenbank, Condensing boiler applications in the process industry, Applied Energy, 89 (2012), pp. 30-36.

[19] L. Fu, G. Tian, J. Sui, and Y. Jiang, Combining absorption heat pump with gas boiler for exhaust condensing heat recovery in district heating system. ACTA Energiae Solaris Sinica, 23-5 (2003), pp.620624.

[20] Engineering Equation Solver user manual 1998.

[21] ORNL, User's guide and reference, modular simulation of absorption systems, 1998.

[22] ASME, Power test codes (PTC) 4.1: Steam generating units. New York, NY: American Society of Mechanical Engineers, 2008.

[23] U.S. Department of Energy commercial reference building models of the national building stock, 2011.

[24] Energy Plus, available on May 19, 2014, http://apps1.eere.energy.gov/buildings/energyplus/.

[25] Bureau of Labor Statistics - Average energy prices in the Philadelphia area - march 2013, available on May 19, 2014, http://www.bls.gov/ro3/apphl.htm.

[26] Electricity Watch - Philadelphia Commercial Electric Rates in 2011, available on May 19, 2014, http://www.electricitywatch.org/philadelphia-commercial-electric-rates-in-2011/. 
[27] D.S. Kim, and C.A. Infante Ferreira, Solar refrigeration options - a state-of-the-art review. International Journal of Refrigeration, 31- 1(2008), pp. 3-15.

[28] M. Mossman, R.S. Means Mechanical Cost Data 2008, $31^{\text {st }}$ edition, Published by Reed Construction Data

[29] P. Waier, T. Baker, B. Balboni B, and R. Bastoni, R.S. Means Building Construction Cost Data, 66th edition, 2008 